\title{
Optimizing the study of tunneled intrapleural catheters for malignant pleural effusions
}

\author{
Todd L. Demmy, MD
}

\author{
From the Department of Thoracic Surgery, Roswell Park Cancer Institute, Buffalo, NY. \\ Received for publication March 3, 2018; revisions received April 9, 2018; accepted for publication April 11, 2018; \\ available ahead of print June 20, 2018. \\ Address for reprints: Todd L. Demmy, MD, Department of Thoracic Surgery, Roswell Park Cancer Institute, Elm \\ and Carlton St, Buffalo, NY 14263 (E-mail: todd.demmy@ roswellpark.org). \\ J Thorac Cardiovasc Surg 2018;156:1255-9 \\ 0022-5223/\$36.00 \\ Copyright (c) 2018 by The American Association for Thoracic Surgery \\ https://doi.org/10.1016/j.jtcvs.2018.04.112
}

Supplemental material is available online.

The optimal therapy for malignant pleural effusions is relatively understudied considering half of patients with cancer develop them during their life span, yielding an annual US/European incidence of 750,000 cases. ${ }^{1,2}$ The challenges studying this disease are numerous and discussed later in this article. Attempting to accelerate pleurodesis by a variety of sclerosis agents was the classic approach and remains popular today. Maintaining lung expansion by a tunneled intrapleural catheter (TIC) so that a pleurodesis could occur naturally began in approximately 1986 with the off-label use of a chemotherapy therapy infusion port and then a peritoneal dialysis catheter in 1994, which was modified to an intended-use device by adding a 1-way valve and popularized by Putnam and colleagues. ${ }^{3}$ Interest in this technology has grown steadily and is preferred at many cancer centers because of the avoidance of inpatient hospitalization, as described in the AMPLE study by Thomas and colleagues. ${ }^{4}$

Before discussing AMPLE, it is important to review briefly the relevant thoracic surgical contributions to cooperative group science that led up to the current study. In the early 1990s, visionary leaders at the Cancer and Leukemia Group B (CALGB) supported introduction of a National Institutes of Health U10 grant organized by Dr David Sugarbaker to both increase the ability of surgical oncologists to participate in clinical trials and enable study of then newly coined "video-assisted thoracic surgery" (VATS, now "thoracoscopic surgery") ). CALGB 9334, which compared chest tube talc slurry with VATS poudrage for malignant pleural effusions, successfully accrued 501 randomized patients, the largest for the lung disease site. ${ }^{6}$ The success of the then relatively novel accrual-based capitated model with payments made directly to its many participating surgeons did not go unnoticed and contributed to disrupting the traditional medical oncology-based cooperative group resource allocations.

CALGB 9334 demonstrated equivalence between bedside talc slurry and VATS pleurodesis, and because there

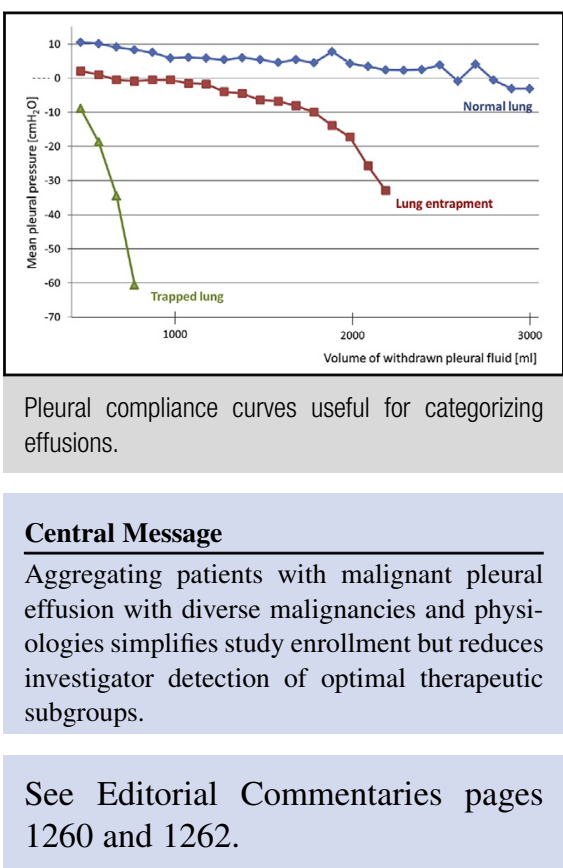

were more pneumonias for those who underwent a general anesthetic, the former became more popular. ${ }^{6}$ However, surgeons today still will opt for a thoracoscopic approach to pleurodesis because of the option to free lung, more precisely apply sclerosant, and obtain tissue for diagnostic studies.

There was naturally an interest in capitalizing on the success of 9334 because the infrastructure for accruing these patients was still in place. Comparing the then only TIC (PleurX, BD, Franklin Lakes, NJ) with the less-invasive talc slurry arm of 9334 seemed like an obvious choice, and CALGB 30102 was born. ${ }^{7}$ In addition to Putnam and colleagues' randomized study, ${ }^{3}$ experience was growing with the use of TIC, and single-institution reports compared its use with talc pleurodesis and suggested benefit for those with trapped lungs. ${ }^{8,9}$ Supporting articles are described in comprehensive reviews and in the Appendix E1. ${ }^{10}$

Unfortunately, CALGB 30102 failed to accrue despite an existing proven infrastructure. In retrospect, failure should have been predictable, and the reason is relevant to this current discussion. ${ }^{7}$ Patients and investigators who had equipoise between 2 inpatient-based therapies no longer tolerated randomization when a TIC arm enabled early discharge or hospitalization avoidance. Although this generated healthy discussions on how to enable an alternative trial design to accommodate the roughly even split of 
patient preference toward each arm, the trial was terminated early. Nevertheless, there was sufficient participation to demonstrate better effusion control for patients with TIC, particularly those with trapped lungs.

The recently published AMPLE trial was well designed and showed a 2-day reduction of hospital stay at 1 year of follow-up for the patients with TIC compared with those who received pleurodesis. ${ }^{4}$ Because TIC is an ongoing therapy, there were fewer reinterventions for pleural effusion in this group. Quality of life was similar (trending better at 12 months for TIC), and the stay reductions roughly equaled that expected by avoiding hospitalization for the initial pleurodesis. Because this difference was approximately one fifth of the total hospitalization required by both groups, the investigators questioned the clinical importance of the results. The randomization scheme attempted to balance patients with known trapped lungs; however, with only 2 to 3 such patients in each arm, referral avoidance for the study seems likely. Of patients screened, $35 \%$ were not eligible with the most common reason being patient refusal. Although accrual was respectable, it took 28 months to complete at 9 high-volume centers, suggesting that there is a larger population of patients who were not referred to be evaluated for this trial.

The results of AMPLE were similar to that of TIME2 published in 2012, which took more than 4 years to recruit 106 patients from 7 UK hospitals. ${ }^{11}$ Notably, dyspnea control was similar at first but favored TIC at 6 months. Quality of life was similar, and hospitalization was less for TIC. ${ }^{11}$ Another randomized trial that needs to be noted is the NVALT-14, which took 34 months to accrue 98 patients from at least 8 different centers. ${ }^{12}$ TIC was not better than talc in terms of the dyspnea score but was superior for hospital stay and reinterventions.

Although we applaud these investigators for their study of an important problem, difficulty with accrual and failure to detect meaningful differences between treatment arms suggest problems with methodology. Although the population being studied is similar in general terms of having a relatively poor survival, it is diverse in terms of 4 major categories (Table 1): ability to achieve pleurodesis, availability of competing technologies, disease and survival-related factors, and socioeconomic/behavioral concerns. The overlapping primary end points are not unlike what we see in the testing of many lung chemotherapeutic agents without controlling for specific driver mutations and other molecular profiles. Although it is beyond the scope of this article to cover all these confounding factors in detail, more nuanced clinical trial design addressing some of the following issues would likely yield better results.

We generally accept that lung entrapment impairs pleurodesis, and thus patients with suspected trapped lung probably are not referred to clinical trials offering pleurodesis. Unfortunately, despite the wide availability of reusable or
TABLE 1. Population diversity factors requiring better documentation or control in malignant pleural effusion trials

\begin{tabular}{l} 
Predictors of pleurodesis \\
Pleural compliance \\
Imaging predictors of entrapment or success \\
Effusion biomarkers favoring pleurodesis \\
Existing chemotherapy use or infection \\
Technology factors \\
Catheter drainage frequency \\
Chest tube or tunneled catheter brands or types \\
Talc formulations \\
Tunnel catheters delivering or embedded with sclerosants \\
Technology-specific complications \\
Overall patient survival influenced by disease or treatment factors \\
Bilateral effusions \\
Tumor stage \\
Catheter tract metastases management \\
Tumor type including genomic prognosticators \\
Talc effect on metabolism \\
Nutrient loss from ongoing drainage \\
Sarcopenia and other causes of dyspnea \\
Complications from therapy \\
Surgical risk \\
Response to chemotherapy \\
Tumor microenvironment and immunocompetence \\
Socioeconomic \\
Cost \\
Patient anxiety and capacity for self-care \\
Caregiver support \\
\hline
\end{tabular}

disposable manometry equipment in hospital settings, quantifying pleural elastance is underused. ${ }^{13}$ Although certain cases of trapped lung are obvious by imaging, gradations of parenchymal stiffness or pleural entrapment remain underappreciated and not quantified or controlled well in pleurodesis trials (Figure 1). Other factors that impair patient survival and the success rate of pleurodesis include imaging findings such as large effusion size, unfavorable histologic types, delays from first presentation to catheter insertion, and effusion chemistry (low $\mathrm{pH}$ and high lactate dehydrogenase). ${ }^{14-17}$ Concerns with TIC drainage causing intercurrent infection in patients receiving chemotherapy have little support. In fact, infections may have a beneficial effect on pleurodesis and survival if they do occur. $^{18-21}$

Related or competing technology factors can influence effusion trials. Although patients may choose to drain their TIC less frequently to reduce discomfort or cost, this has an adverse effect on achieving pleurodesis. ${ }^{22}$ Less-expensive catheter options including central venous catheters reduce patient cost but are not as well validated. ${ }^{23-25}$ Catheters fused with sclerosis agents such as silver nitrate or hybrid rapid pleurodesis protocols are becoming more popular to shorten the duration of TIC therapy. ${ }^{26-28}$ Finally, TICrelated pleural loculations are relatively common and 


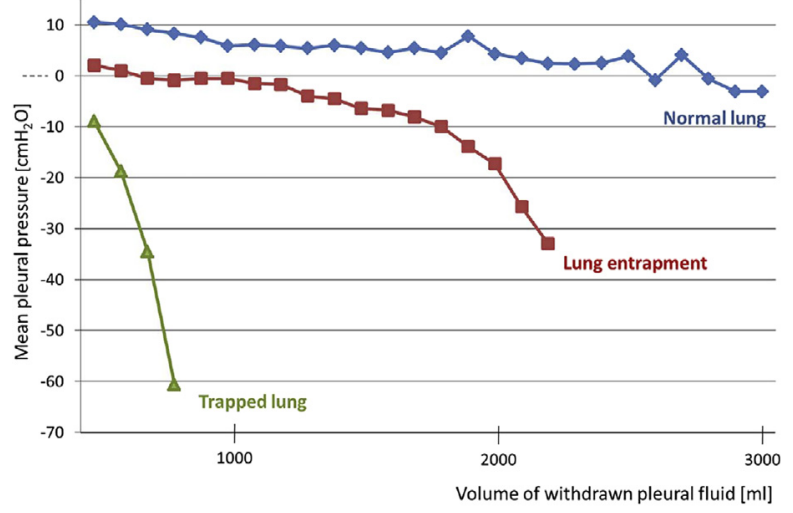

FIGURE 1. Pleural elastance curves that are useful to predict success with pleurodesis. "Lung entrapment" occurs along the spectrum from a normal organ to the final stage of "trapped lung," which is generally irreversible without an intervention like decortication. ${ }^{13}$ "Lung entrapment" may be reversible depending on how effectively the process causing it (eg, parenchymal or pleural inflammation) can be treated. Reprinted with permission. ${ }^{13}$

managed safely with intrapleural fibrinolytics (some bleeding risk) but lack uniform guidelines between institutions. $^{4,29}$

Specific disease and survival factors correlated with pleural effusions require better control as well. Bilateral pleural effusions carry a 2.5 times higher risk of shortterm death and thus often excluded from such trials; yet, they are common enough to deserve study. ${ }^{30}$ Controlling for the totality of metastatic disease burden, which can differ between lung and other metastatic pleural tumors, is important. ${ }^{31}$ Although TIC tract metastases may occur (especially with mesothelioma), prospective randomized evidence does not support routine use of prophylactic radiotherapy. ${ }^{32-34}$ Likewise, although implanting devices has been a concern in patients with hematologic malignancy, this may be less of a concern for TIC. ${ }^{35,36}$ Talc, on the other hand, remains a relatively heterogeneous product that should be delivered with large particle gradation to prevent systemic distribution. ${ }^{37}$ Talc creates acute and chronic increased metabolism in the mediastinal lymph nodes and pleura, and it is unknown to what extent this might usurp precious remaining metabolic capacity in patients dying of advanced malignancy. ${ }^{38,39}$ Furthermore, talc is distributed less well as a slurry despite rolling the patient. $^{40,41}$ Homogeneous slurry dispersion might be achieved by its incorporation into a foaming product that is under development. ${ }^{42}$ Although the metabolic demand and protein malnutrition that go along with chronic pleural drainage are theoretic concerns, it has not been borne out in limited studies for TIC for malignant or benign disease. ${ }^{43,44}$

Fit patients can be relatively asymptomatic with lung opacification, and patients dying of cancer often experience breathlessness with full pulmonary expansion. The latter results from a convergence of associated diseases such as chronic obstructive pulmonary disease, sarcopenia with deconditioning, and wasting of respiratory muscles. ${ }^{45}$ Unfortunately, these factors distort the dyspnea and reduced quality of life scales measured in pleural effusion studies. They need to be quantified better by functional testing and muscle imaging acceptable to participants so that the relative benefit of effusion drainage can be assessed. Effusion control-related adverse outcomes such as infections need better quantification by objective grading systems and validated surveys to assess their specific effects on quality of life. Serially linking the readily available biomarkers from the effusion microenvironment to outcomes is also critical. Finally, better overall classification of the metastatic patient needs consideration given the emergence of personalized targeted therapies, immunotherapy, totality of metastatic burden, and resistance to chemotherapy. ${ }^{37}$

Because our methodologies fail to demonstrate effusioncontrol methods better in terms of survival or quality of life, idiosyncratic patient socioeconomic and behavioral factors become more important in decision process. Costs between pleurodesis and TIC break roughly even in multiple studies unless a short survival is predictable, and then TIC may be better. ${ }^{46-50}$ Patients who have difficulty affording drainage kits may reduce the aspiration frequency and paradoxically increase their expense by prolonging the time to pleurodesis. Less well documented but evident to those who counsel patients and their caregivers is the dichotomy of concerns regarding prolonged personal care of a transcutaneous device and avoidance of hospitalization. ${ }^{51}$ Desires for rapid resolutions, available support visits from nurses or family, previous medical or equivalent experiences, education levels, and abilities to adopt new skills (that may be impaired in older individuals) all influence patient decisions.

Going back to the AMPLE trial in which hospitalization served as a surrogate for reduced quality of life, the reader may wonder whether participants later perceived the extra 2 days of hospitalization for pleurodeses as value added because of the potential to avoid ongoing therapies or self-management of an external device. Instruments that capture this patient sentiment would be welcome.

The AMPLE trial article mentions AMPLE-2, which attempts to determine the optimal frequency of TIC drainage, and the recently published IPC-Plus study showing talc slurry instilled by an indwelling pleural catheter accelerates pleurodesis and catheter removal. ${ }^{1,4}$ An additional trial, OPTIMUM, is a randomized trial using quality of life as the primary end point comparing outpatient talc through an indwelling pleural catheter with inpatient management. ${ }^{52}$

Although ongoing randomized pleurodesis clinical trials are useful, it is important to realize that many patients are not eligible or avoid them because of lung entrapment or the numerous reasons noted earlier. Our trials do not 
adequately account for diversity of the population with this problem. We fail to adequately measure parameters such as pleural elastance or use biomarkers that predict rapid pleurodesis and prolonged survival. In addition, because patients often feel better immediately after fluid drainage, we often miss sarcopenia, comorbidities, and other manifestations of extensive malignancy that soon dominate to interfere with the long-term palliation goals that are primary end points in many of these studies. We need to add a more granular and holistic approach to symptom management and patient selection if we are to improve our understanding of this important problem. Arguably, a detailed prospective registry better capturing the items listed in Table 1 may be what we should be focusing on now to generate hypotheses that will yield more meaningful future trial results.

\section{Conflict of Interest Statement}

T.L.D. is a Medtronic consultant.

The author thanks Drs Sai Yendamuri, Leslie Kohman, and Glenn Laub for assistance with the preparation of this article.

\section{References}

1. Bhatnagar R, Keenan EK, Morley AJ, Kahan BC, Stanton AE, Haris M, et al. Outpatient talc administration by indwelling pleural catheter for malignant effusion. N Engl J Med. 2018;378:1313-22.

2. Bertolaccini L, Viti A, Gorla A, Terzi A. Home-management of malignant pleural effusion with an indwelling pleural catheter: ten years experience. Eur J Surg Oncol. 2012;38:1161-4.

3. Putnam JB Jr, Light RW, Rodriguez RM, Ponn R, Olak J, Pollak JS, et al. A randomized comparison of indwelling pleural catheter and doxycycline pleurodesis in the management of malignant pleural effusions. Cancer. 1999;86:1992-9.

4. Thomas R, Fysh ETH, Smith NA, Lee P, Kwan BCH, Yap E, et al. Effect of an indwelling pleural catheter vs talc pleurodesis on hospitalization days in patients with malignant pleural effusion: the AMPLE randomized clinical trial. JAMA. 2017;318:1903-12.

5. Kohman LJ. Cancer and leukemia group B surgery committee. Clin Cancer Res. 2006;12(11 Pt 2):3622s-7s.

6. Dresler CM, Olak J, Herndon JE II, Richards WG, Scalzetti E, Fleishman SB, et al. Phase III intergroup study of talc poudrage vs talc slurry sclerosis for malignant pleural effusion. Chest. 2005;127:909-15.

7. Demmy TL, Gu L, Burkhalter JE, Toloza EM, D'Amico TA, Sutherland S, et al Optimal management of malignant pleural effusions (results of CALGB 30102). J Natl Compr Canc Netw. 2012;10:975-82.

8. Ohm C, Park D, Vogen M, Bendick P, Welsh R, Pursel S, et al. Use of an indwelling pleural catheter compared with thoracoscopic talc pleurodesis in the management of malignant pleural effusions. Am Surg. 2003;69:198-202.

9. Pien GW, Gant MJ, Washam CL, Sterman DH. Use of an implantable pleural catheter for trapped lung syndrome in patients with malignant pleural effusion. Chest. 2001;119:1641-6.

10. Ost DE, Niu J, Zhao H, Grosu HB, Giordano SH. Quality gaps and comparative effectiveness of management strategies for recurrent malignant pleural effusions. Chest. 2018;153:438-52.

11. Davies HE, Mishra EK, Kahan BC, Wrightson JM, Stanton AE, Guhan A, et al. Effect of an indwelling pleural catheter vs chest tube and talc pleurodesis for relieving dyspnea in patients with malignant pleural effusion: The TIME2 randomized controlled trial. JAMA. 2012;307:2383-9.

12. Boshuizen RC, Vd Noort V, Burgers JA, Herder GJM, Hashemi SMS, Hiltermann TJN, et al. A randomized controlled trial comparing indwelling pleural catheters with talc pleurodesis (NVALT-14). Lung Cancer. 2017;108: 9-14.

13. Grabczak EM, Krenke R, Zielinska-Krawczyk M, Light RW. Pleural manometry in patients with pleural diseases-the usefulness in clinical practice. Respir Med. January 31, 2018 [Epub ahead of print].
14. Fysh ETH, Bielsa S, Budgeon CA, Read CA, Porcel JM, Maskell NA, et al. Pre dictors of clinical use of pleurodesis and/or indwelling pleural catheter therapy for malignant pleural effusion. Chest. 2015;147:1629-34.

15. Warren WH, Kim AW, Liptay MJ. Identification of clinical factors predicting PleurX catheter removal in patients treated for malignant pleural effusion. Eur J Cardiothorac Surg. 2008;33:89-94.

16. Wong WM, Tam TC, Wong MK, Lui MM, Ip MS, Lam DC. Managing malignant pleural effusion with an indwelling pleural catheter: factors associated with spontaneous pleurodesis. Hong Kong Med J. 2016;22:334-40.

17. Verma A, Phua CK, Sim WY, Algoso RE, Tee KS, Lew SJ, et al. Pleural LDH as a prognostic marker in adenocarcinoma lung with malignant pleural effusion. Medicine (Baltimore). 2016;95:e3996.

18. Hak CC, Sivakumar P, Ahmed L. Safety of indwelling pleural catheter use in patients undergoing chemotherapy: a five-year retrospective evaluation. BMC Pulm Med. 2016;16:41.

19. Fysh ETH, Tremblay A, Feller-Kopman D, Mishra EK, Slade M, Garske L, et al. Clinical outcomes of indwelling pleural catheter-related pleural infections: an international multicenter study. Chest. 2013;144:1597-602.

20. Wilshire CL, Gilbert CR, Louie BE, Aye RW, Farivar AS, Vallieres E, et al. Tunneled pleural catheter use for pleural palliation does not increase infection rate in patients with treatment-related immunosuppression. Support Care Cancer. 2018;26:1525-31.

21. Bibby AC, Clive AO, Slade GC, Morley AJ, Fallon J, Psallidas I, et al. Survival in patients with malignant pleural effusions who developed pleural infection: a retrospective case review from six UK centers. Chest. 2015;148:235-41.

22. Wahidi MM, Reddy C, Yarmus L, Feller-Kopman D, Musani A, Shepherd RW, et al. Randomized trial of pleural fluid drainage frequency in patients with malignant pleural effusions. the ASAP trial. Am J Respir Crit Care Med. 2017;195: 1050-7.

23. Dhaliwal I, Mahdavian M, Asghari S. Chun To Wong B, Labelle R, Amjadi K. Management of malignant pleural effusion with ASEPT(R) pleural catheter: quality of life, feasibility, and patient satisfaction. Can Respir J. 2016;2016: 4273480 .

24. Chetty GK, Elahi MM, Siddagangaiah V, Leverment JN. Bonanno's catheter: a less invasive and cost-effective alternative for drainage of pleural effusion. J Thorac Cardiovasc Surg. 2005;129:219-20.

25. Yazdanbod A, Salehifar A, Maleki N, Habibzadeh S, Tavosi Z. Successful use of central venous catheters in the management of recurrent malignant pleural effusions: one new option. Support Care Cancer. 2015;23:2267-71.

26. Bhatnagar R, Zahan-Evans N, Kearney C, Edey AJ, Stadon LJ, Tremblay A, et al. A novel drug-eluting indwelling pleural catheter for the management of malig nant effusions. Am J Respir Crit Care Med. 2018;197:136-8.

27. Krochmal R, Reddy C, Yarmus L, Desai NR, Feller-Kopman D, Lee HJ. Patient evaluation for rapid pleurodesis of malignant pleural effusions. J Thorac Dis. 2016;8:2538-43.

28. Jones DR, Taylor MD, Petroni GR, Shu J, Burks SG, Daniel TM, et al. Phase I trial of intrapleural docetaxel administered through an implantable catheter in subjects with a malignant pleural effusion. J Thorac Oncol. 2010;5:75-81.

29. Lui MM, Thomas R, Lee YC. Complications of indwelling pleural catheter use and their management. BMJ Open Respir Res. 2016;3:e000123.

30. DeBiasi EM, Pisani MA, Murphy TE, Araujo K, Kookoolis A, Argento AC, et al Mortality among patients with pleural effusion undergoing thoracentesis. Eur Re spir J. 2015;46:495-502.

31. Liou DZ, Serna-Gallegos D, Chan JL, Borgella J, Akhmerov S, Soukiasian HJ Survival difference in patients with malignant pleural effusions treated with pleural catheter or talc pleurodesis. Am Surg. 2016;82:995-9.

32. Tobin CL, Thomas R, Chai SM, Segal A, Lee YC. Histopathology of removed indwelling pleural catheters from patients with malignant pleural diseases. Respirology. 2016;21:939-42.

33. Clive AO, Taylor H, Dobson L, Wilson P, de Winton E, Panakis N, et al. Prophylactic radiotherapy for the prevention of procedure-tract metastases after surgical and large-bore pleural procedures in malignant pleural mesothelioma (SMART): a multicentre, open-label, phase 3, randomised controlled trial. Lancet Oncol. 2016; 17:1094-104.

34. Janes SM, Rahman NM, Davies RJ, Lee YC. Catheter-tract metastases associated with chronic indwelling pleural catheters. Chest. 2007;131:1232-4.

35. Faiz SA, Pathania P, Song J, Li L, Balachandran DD, Ost DE, et al. Indwelling pleural catheters for patients with hematologic malignancies. A 14-year, single-center experience. Ann Am Thorac Soc. 2017;14:976-85. 
36. Gilbert CR, Lee HJ, Skalski JH, Maldonado F, Wahidi M, Choi PJ, et al. The use of indwelling tunneled pleural catheters for recurrent pleural effusions in patients with hematologic malignancies: a multicenter study. Chest. 2015;148:752-8.

37. Zarogoulidis K, Zarogoulidis P, Darwiche K, Tsakiridis K, Machairiotis N, Kougioumtzi I, et al. Malignant pleural effusion and algorithm management. $J$ Thorac Dis. 2013;5(Suppl 4):S413-9.

38. Wang Y, Carter BW, Muse V, Digumarthy S, Shepard JA, Sharma A. Potential pitfall in the assessment of lung cancer with FDG-PET/CT: talc pleurodesis causes intrathoracic nodal FDG avidity. Lung Cancer Int. 2013;2013: 683582.

39. Vandemoortele T, Laroumagne S, Roca E, Bylicki O, Dales JP, Dutau H, et al. Positive FDG-PET/CT of the pleura twenty years after talc pleurodesis: three cases of benign talcoma. Respiration. 2014;87:243-8.

40. Mager HJ, Maesen B, Verzijlbergen F, Schramel F. Distribution of talc suspension during treatment of malignant pleural effusion with talc pleurodesis. Lung Cancer. 2002;36:77-81.

41. Stefani A, Natali P, Casali C, Morandi U. Talc poudrage versus talc slurry in the treatment of malignant pleural effusion. A prospective comparative study. Eur J Cardiothorac Surg. 2006;30:827-32.

42. Laub GW, Huneke RB, Kresh JK, Kanack CJ, Remold ES, Salvino JM. A novel triblock copolymer hydrogel foam delivery system to improve talc pleurodesis efficacy. Proceedings of the American College of Surgeons Clinical Congress, San Diego, California, October 22-26, 2017.

43. Fysh ETH, Waterer GW, Kendall PA, Bremner PR, Dina S, Geelhoed E, et al. Indwelling pleural catheters reduce inpatient days over pleurodesis for malignant pleural effusion. Chest. 2012;142:394-400.
44. Chambers DM, Abaid B, Gauhar U. Indwelling pleural catheters for nonmalignant effusions: Evidence-based answers to clinical concerns. Am J Med Sci. 2017;354:230-5.

45. Dudgeon D, Baracos VE. Physiological and functional failure in chronic obstructive pulmonary disease, congestive heart failure and cancer: a debilitating intersection of sarcopenia, cachexia and breathlessness. Curr Opin Support Palliat Care. 2016;10:236-41.

46. Rial MB, Lamela IP, Fernandez VL, Arca JA, Delgado MN, Pombo CV, et al Management of malignant pleural effusion by an indwelling pleural catheter: a cost-efficiency analysis. Ann Thorac Med. 2015;10:181-4.

47. Puri V, Pyrdeck TL, Crabtree TD, Kreisel D, Krupnick AS, Colditz GA, et al. Treatment of malignant pleural effusion: a cost-effectiveness analysis. Ann Thorac Surg. 2012;94:374-80.

48. Penz ED, Mishra EK, Davies HE, Manns BJ, Miller RF, Rahman NM Comparing cost of indwelling pleural catheter vs talc pleurodesis for malignan pleural effusion. Chest. 2014;146:991-1000.

49. Olden AM, Holloway R. Treatment of malignant pleural effusion: PleurX catheter or talc pleurodesis? A cost-effectiveness analysis. J Palliat Med. 2010;13:59-65.

50. Olfert JA, Penz ED, Manns BJ, Mishra EK, Davies HE, Miller RF, et al. Cost effectiveness of indwelling pleural catheter compared with talc in malignant pleural effusion. Respirology. 2017;22:764-70.

51. Murthy SC, Rice TW. Surgical management of malignant pleural effusions Thorac Surg Clin. 2013;23:43-49, vi.

52. Sivakumar P, Douiri A, West A, Rao D, Warwick G, Chen T, et al. OPTIMUM: A protocol for a multicentre randomised controlled trial comparing out patient talc slurry via indwelling pleural catheter for malignant pleural effusion vs usual inpatient management. BMJ Open. 2016;6:e012795. 


\section{APPENDIX E1}

\begin{tabular}{ll}
\hline $\begin{array}{c}\text { Supplemental citations in descending order of } \\
\text { year published }\end{array}$ & \\
\hline Tunneled pleural catheter original research studies & E1-E14 \\
\hline Tunneled pleural catheter reviews and meta-analyses & E15-E23 \\
\hline
\end{tabular}

\section{E-References}

E1. Kyskan R, Li P, Mulpuru S, Souza C, Amjadi K. Safety and performance characteristics of outpatient medical thoracoscopy and indwelling pleural catheter insertion for evaluation and diagnosis of pleural disease at a tertiary center in Canada. Can Respir J. 2017;2017:9345324.

E2. Boujaoude Z, Bartter T, Abboud M, Pratter M, Abouzgheib W. Pleuroscopic pleurodesis combined with tunneled pleural catheter for management of malignant pleural effusion: a prospective observational study. J Bronchology Interv Pulmonol. 2015;22:237-43.

E3. Lorenzo MJ, Modesto M, Perez J, Bollo E, Cordovilla R, Munoz M, et al. Quality-of-life assessment in malignant pleural effusion treated with indwelling pleural catheter: a prospective study. Palliat Med. 2014;28:326-34.

E4. Freeman RK, Ascioti AJ, Mahidhara RS. A propensity-matched comparison of pleurodesis or tunneled pleural catheter in patients undergoing diagnostic thoracoscopy for malignancy. Ann Thorac Surg. 2013;96:259-64.

E5. Hunt BM, Farivar AS, Vallieres E, Louie BE, Aye RW, Flores EE, et al. Thoracoscopic talc versus tunneled pleural catheters for palliation of malignant pleural effusions. Ann Thorac Surg. 2012;94:1053-9.

E6. Suzuki K, Servais EL, Rizk NP, Solomon SB, Sima CS, Park BJ, et al. Palliation and pleurodesis in malignant pleural effusion: the role for tunneled pleural catheters. J Thorac Oncol. 2011;6:762-7.

E7. Sioris T, Sihvo E, Salo J, Rasanen J, Knuuttila A. Long-term indwelling pleural catheter (PleurX) for malignant pleural effusion unsuitable for talc pleurodesis. Eur J Surg Oncol. 2009;35:546-51.

E8. Efthymiou CA, Masudi T, Thorpe JA, Papagiannopoulos K. Malignant pleural effusion in the presence of trapped lung: five-year experience of PleurX tunnelled catheters. Interact Cardiovasc Thorac Surg. 2009;9:961-4.
E9. Schneider T, Reimer P, Storz K, Klopp M, Pfannschmidt J, Dienemann H, et al. Recurrent pleural effusion: who benefits from a tunneled pleural catheter? Thorac Cardiovasc Surg. 2009;57:42-6.

E10. Tremblay A, Michaud G. Single-center experience with 250 tunnelled pleural catheter insertions for malignant pleural effusion. Chest. 2006;129:362-8.

E11. Musani AI, Haas AR, Seijo L, Wilby M, Sterman DH. Outpatient management of malignant pleural effusions with small-bore, tunneled pleural catheters. Respiration. 2004;71:559-66.

E12. Putnam JB Jr, Walsh GL, Swisher SG, Roth JA, Suell DM, Vaporciyan AA, et al. Outpatient management of malignant pleural effusion by a chronic indwelling pleural catheter. Ann Thorac Surg. 2000;69:369-75.

E13. Robinson RD, Fullerton DA, Albert JD, Sorensen J, Johnston MR. Use of pleural Tenckhoff catheter to palliate malignant pleural effusion. Ann Thorac Surg. 1994;57:286-8.

E14. Hussain SA, Burton GM, Yuce M. Symptomatic loculated malignant pleural effusion treatment with indwelling Tenckhoff catheter. Chest. 1990;97:766-7.

E15. Murthy V, Bessich JL. Medical thoracoscopy and its evolving role in the diagnosis and treatment of pleural disease. J Thorac Dis. 2017;9(Suppl 10): S1011-21.

E16. Desai NR, Lee HJ. Diagnosis and management of malignant pleural effusions: state of the art in 2017. J Thorac Dis. 2017;9(Suppl 10):S1111-22.

E17. Argento AC, Schembri F. The evolving role of the indwelling tunneled pleural catheter. A means to an end. Am J Respir Crit Care Med. 2017;195:976-8.

E18. Patil M, Dhillon SS, Attwood K, Saoud M, Alraiyes AH, Harris K. Management of benign pleural effusions using indwelling pleural catheters: a systematic review and meta-analysis. Chest. 2017;151:626-35.

E19. Kheir F, Shawwa K, Alokla K, Omballi M, Alraiyes AH. Tunneled pleural catheter for the treatment of malignant pleural effusion: a systematic review and meta-analysis. Am J Ther. 2016;23:e1300-6.

E20. Krishnan M, Cheriyath P, Wert Y, Moritz TA. The untapped potential of tunneled pleural catheters. Ann Thorac Surg. 2015;100:2055-7.

E21. Fortin M, Tremblay A. Pleural controversies: indwelling pleural catheter vs. pleurodesis for malignant pleural effusions. J Thorac Dis. 2015;7:1052-7.

E22. Van Meter ME, McKee KY, Kohlwes RJ. Efficacy and safety of tunneled pleural catheters in adults with malignant pleural effusions: a systematic review. J Gen Intern Med. 2011;26:70-6.

E23. MacEachern P, Tremblay A. Pleural controversy: pleurodesis versus indwelling pleural catheters for malignant effusions. Respirology. 2011;16:747-54. 